DOI: $10.2478 / \mathrm{v} 10129-011-0023-0$

S. Martyniuk, J. Oroń, M. Kozieł

Department of Agricultural Microbiology, Institute of Soil Science and Plant

Cultivation - State Research Institute, 24-100 Puławy, Poland

\title{
FUNGI, INCLUDING FUSARIUM SPP., ON EARS OF CONVENTIONALLY AND ECOLOGICALLY GROWN WINTER WHEAT
}

\begin{abstract}
Ears of winter wheat cultivars (Bogatka and Legenda) grown under conventional and ecological (organic) farming systems, were sampled at different developmental stages and examined for their colonization by filamentous fungi, including Fusarium spp. Ears samples were shaken in sterile water containing $0.01 \%$ of Tween 80 and appropriate 10-fold dilutions of the initial suspension were inoculated onto agar medium containing antibiotics to inhibit bacterial contaminants. After 6-7 days of incubation at $28^{\circ} \mathrm{C}$ fungal colonies were counted and after further 4 days fragments of colonies were transferred onto other media for identification. On ears at flowering no Fusarium species were found in 2008 with dry and hot July, but in 2009 with more frequent rainfalls in July Fusarium poae, $F$. tricinctum and $F$. avenaceum were detected on winter wheat ears at the flowering stage. At the hard kernel stage the following species were isolated from winter wheat ears: $F$. poae and $F$. sporotrichioides in 2008 (17 and 18 isolates respectively) and $F$. avenacum, $F$. crookwellense, $F$ poae, $F$. sporotrichioides and $F$. tricinctum in 2009 (2, 18, 39, 2 and 17 isolates respectively, and 9 unidentified Fusarium). In 2008 more Fusarium spp. were found on winter wheat ears grown under the conventional system than under the ecological (organic) system. In the ecological system wheat stands are thinner but taller (due to the lack of any mineral fertilizers and plant growth regulators) and in consequence winter wheat ears in this system may keep moisture shorter than those in the conventional system. It seems that this difference may be the most important factor influencing colonization of winter wheat ears by Fusarium spp. and other fungi under the compared farming systems.
\end{abstract}

Key words: ears, farming system, fungi, Fusarium spp., winter wheat

\section{INTRODUCTION}

Divers and numerous communities of microorganisms including bacteria, yeasts, filamentous fungi and algae can be found on leaves and other above-

Communicated by Edward Arseniuk 
ground parts of plants. The majority of these microorganisms, called epiphytes, have no detectable effect on plant growth and function, some of them are beneficial whereas others with the ability to infect plant tissues may be damaging to the host plant (Megan and Lacey 1986, Dik et al. 1992, Lindow and Brandl 2003). Epiphytes encounter rather harsh conditions on plant surfaces, where they are exposed to fluxes of UV radiation, rapidly fluctuating temperature and humidity, as well as to a strong competition for limited nutrient sources (Lindow and Brandl 2003). In the case of field grown crops densities and composition of microbial populations on their aerial parts depend also on agricultural practices, such as mineral fertilization or spraying with plant protection chemicals. Fokkema et al. (1983, 1987) and Dik et al. $(1991,1992)$ in their extensive studies have proved that pink and white yeasts, predominating in the saprophytic phyllosphere communities colonizing wheat leaves, were effective in removing aphid honeydew and other nutrients from wheat leaves, which resulted in the suppression of necrotrophic pathogens and higher crop yields. Magan and Lacey (1985) reported that flag leaves and ears of spring and winter wheat were colonized by high populations of yeasts and yeast-like fungi, while within filamentous fungi predominated Cladosporium spp., Alternaria alternata, Vetricillium lecanti and Fusarium spp. These authors have also shown that some fungicides can significantly reduce fungal populations on flag leaves and ears, with yeasts and Cladosporium spp. being the most sensitive fungi to such treatments. In Poland Łukanowski and Sadowski (2005) have found more Fusarium spp. on grains of winter wheat grown under conventional and integrated farming system than under ecological system. It seems possible that fungicides applied to control fungal diseases in conventional farming systems reduce populations and thus competitive potential of saprophytic fungi, e.g. yeasts, facilitating in this way infection of winter wheat ears (and grains) with other fungi, including toxinogenic Fusarium spp. Using the same field experiment described by Łukanowski and Sadowski (2005) we have done a preliminary examination of populations of microorganisms occurring on ears of two winter wheat cultivars (Roma and Zyta) grown in this experiment (Martyniuk et al., 2009). It was found that populations of saprophytic fungi, particularly yeasts, on ears grown under conventional (intensive) system were not significantly reduced by fungicides applied in this system as compared to the organic farming system. However, qualitative analyses of the mycelial fungi have shown that heads of winter wheat under the conventional system were more intensively colonized with Fusarium species than heads under the ecological system. In this paper we preset results of our further studies on fungal communities colonizing winter wheat ears at various stages of their development as influenced by farming systems (conventional versus ecological). 


\section{MATERIAL AND METHODS}

\section{Field experiment}

The studies were based on a long-term (established in 1994) field experiment located on a brown soil (Albic Luvisol) at the IUNG-PIB Experimental Station in Osiny $\left(51^{\circ} 27^{\prime} \mathrm{N} ; 22^{\circ} 2^{\prime} \mathrm{E}\right.$, Lublin voivodeship). In this experiment various crops are grown under three different farming systems: conventional, integrated and ecological (Martyniuk et al., 2001; Kuś et al, 2007). For the purpose of these studies ears of two winter wheat cultivars (Bogatka and Legenda ) grown under conventional and ecological farming systems were sampled in 2008 and 2009. In the conventional farming system (CFS) the following crop rotation is used: winter rape - spring barley - winter wheat. In this system winter wheat was grown according to the high input technology generally used by farmers in Poland, which included two applications of fungicides. In 2008 the first spray of winter wheat plants with fungicides (Tilt Plus + Unix $75 \mathrm{WG}$ ) was performed on May 7 and the second application of Prosaro 250EC took place on May 30. In 2009 Impet 460EC was sprayed on May 7 and Prosaro 250EC on June 1. In the ecological farming system (EFS) the crop rotation includes: potato spring wheat - grass/red clover mixture ( 2 years) - winter wheat. All crops, including winter wheat, in this system are grown without any applications of synthetic mineral fertilizers and plant protection chemicals.

\section{Sampling of ears and microbial analyses}

Ears of winter wheat were sampled four times during 2008 and 2009 at the following growth stages (Zadoks): I - heading (GS 57-59), II - flowering (GS 65-69), III milk kernel (GS 73-75) and IV - ripening (GS 91-93). Three samples, each consisting of 10 ears, were randomly collected from fields of both winter wheat cultivars (Bogatka and Legenda). Ear samples were placed in disinfected plastic bags and within 2 hours they were brought to the laboratory and refrigerated at $4^{\circ} \mathrm{C}$. Next day ears were cut into small fragments and $10 \mathrm{~g}$ samples were placed in $300 \mathrm{ml}$ glass bottles containing $90 \mathrm{ml}$ of autoclaved water with the addition of $0.01 \%$ Tween 80 (Dik et al. 1992). The content of the bottles was agitated for $30 \mathrm{~min}$ on a rotary shaker at $200 \mathrm{rev}$ per min. The resultant suspensions were than serially diluted (10-fold dilutions) and from appropriate dilutions aliquots of $0.1 \mathrm{ml}$ were inoculated onto the surface of agar medium in Petri plates to assess numbers of yeasts and filamentous fungi occurring on the examined ears. Basal yeast agar (BYA) medium containing $20 \mathrm{~g}$ glucose, $1 \mathrm{~g}$ yeast extract (Difco), $10 \mathrm{~g}$ proteose peptone (Difco), $15 \mathrm{~g}$ agar and $10^{6}$ i.u. streptomycin sulphate per liter was used (Dik et al., 1992). Fungal colonies were counted after 6-7 days of incubation at $27^{\circ} \mathrm{C}$. Numbers of both groups of fungi were expressed as colony forming units (cfu) per $1 \mathrm{~g}$ of ear d.m. Colonies of filamentous fungi were transferred onto fresh BYA slants and identified using the following manuals: Domsch et al. (1980), Kwaśna et al. (1991), Leslie and Summerell (2006). The analysis of variance 
(ANOVA) and Tukey's test $(\alpha=0.05)$ were used to determine the significance of differences between the farming systems and winter wheat cultivars.

\section{RESULTS}

In 2008 the first sampling of winter wheat ears was done on June 2 when heading was almost complete (GS 57-59) and at this stage of ears development significantly higher numbers (cfu) of fungi (yeasts and filamentous) were found on ears of both cultivars grown in the conventional farming system (CFS) than in the ecological system (EFS). However, at the flowering and milk kernel stages the opposite was true - winter wheat ears under CFS were colonized by lower populations of fungi than those under the EFS (Table 1). At full ripeness winter wheat ears of both cultivars grown in the compared farming systems were colonized by similar populations of total fungi, but at this stage and also at the previous one the ears of cv. Legenda harboured lower numbers of fungi as compared to cv. Bogatka in both farming systems (Table 1). At the heading and flowering stages on ears of both winter wheat cultivars relatively moderate numbers of fungal propagules were found but the abundance of these microorganisms progressively increased during ripening of ears and at the final sampling (GS 9193) fungal populations on ears were high, reaching 1.9-3.7 x $10^{6} \mathrm{cfu}$ per $1 \mathrm{~g}$ of ears d.m. (Table 1).

Table 1

Total numbers of fungi (cfu $\times 10^{4}$ ) including yeasts (in brackets) on winter wheat ears (1 $\mathrm{g}$ d.m.) as influenced by their developmental stages and cultivation system (2008)

\begin{tabular}{|c|c|c|c|c|}
\hline \multirow{2}{*}{ Cultivation system } & \multicolumn{4}{|c|}{ Growth stage } \\
\hline & Heading & Flowering & Milk kernels & Hard kernels \\
\hline \multicolumn{5}{|c|}{ Cultivar Bogatka } \\
\hline Conventional & $1.75(0.50)$ & $0.33(0.26)$ & $15.00(14.46)$ & $343(277)$ \\
\hline Ecological & $0.43(0.09)$ & $0.88(0.71)$ & $31.60(30.49)$ & 367 (307) \\
\hline \multicolumn{5}{|c|}{ Cultivar Legenda } \\
\hline Conventional & $1.56(0.32)$ & $0.42(0.29)$ & $8.96(8.68)$ & $220(193)$ \\
\hline Ecological & $0.68(0.21)$ & $0.92(0.80)$ & $11.89(11.37)$ & $260(223)$ \\
\hline $\operatorname{LSD}_{(0.05)}$ & 0.8 & 0.43 & 4.68 & n.s. \\
\hline for: cultiv. system & $(0.4)$ & $(0.44)$ & $(4.75)$ & n.s. \\
\hline $\operatorname{LSD}_{(0.05)}$ & n.s & n.s. & 4.68 & 121 \\
\hline for: cultivar & (n.s.) & (n.s.) & $(4.76)$ & (110) \\
\hline $\operatorname{LSD}_{(0.05)}$ for cultiv. & n.s. & n.s. & 6.61 & n.s. \\
\hline syst. $\times$ cultivar & (n.s.) & (n.s.) & $(6.73)$ & (n.s.) \\
\hline
\end{tabular}


The qualitative analysis of filamentous fungi occurring on winter wheat ears in 2008 has shown that at the heading, flowering and milk kernel stages Cladosporium herbarum predominated on the ears of both cultivars (Table 2). At heading more isolates of this fungus were obtained from winter wheat ears grown in CFS than in EFS, but at other growth stages $C$. herbarum was more numerous on EFS ears than on CFS ones. In 2008 fungi from the genus Fusarium were isolated for the first time from ears being at the milk kernel stage of their development and all three isolates were identified as $F$. poae (Table 2). At ripening 35 Fusarium isolates were obtained and they belonged to the following species: $F$. poae (17 isolates) and $F$. sporotrichioides (18 isolates). At this stage more Fusarium spp. were found on the ears of both winter wheat cultivars grown in CFS than in EFS (Table 2).

Number of filamentous fungi isolates* obtained from winter wheat ears as influenced by their developmental stages and cultivation system $(\mathrm{E}=$ ecological, $\mathrm{C}=$ conventional, 2008)

\begin{tabular}{|c|c|c|c|c|}
\hline Fungus & Legenda E & Legenda $\mathrm{C}$ & Bogatka E & Bogatka C \\
\hline \multicolumn{5}{|c|}{ Heading } \\
\hline Cladosporium herbarum & 2 & 8 & -- & 8 \\
\hline Penicillium sp. & -- & -- & 1 & 1 \\
\hline Non-sporulating fungi & 2 & 3 & 3 & 4 \\
\hline \multicolumn{5}{|c|}{ Flowering } \\
\hline Cladosporium herbarum & -4 & 2 & 5 & -6 \\
\hline Aspergillus sp. & 2 & 1 & -- & -- \\
\hline Penicillum sp. & -- & -1 & - & 1 \\
\hline Non-sporulating fungi & -- & -- & 2 & -- \\
\hline \multicolumn{5}{|c|}{ Milk kernels } \\
\hline Alternaria alternata & - & - & - & 1 \\
\hline Cladosporium herbarum & 13 & 2 & 23 & 2 \\
\hline Fusarium poae & 1 & 1 & 1 & - \\
\hline Non-sporulating fungi & 2 & 3 & - & 6 \\
\hline \multicolumn{5}{|c|}{ Hard kernels } \\
\hline Alternaria alternata & 11 & 6 & 29 & 22 \\
\hline Aspergillus sp. & 8 & -- & -- & -- \\
\hline Cladosporium herbarum & 60 & 47 & 72 & 78 \\
\hline Fusarium poae & 1 & -- & 2 & 14 \\
\hline Fusarium sporotrichioides & -- & 11 & 1 & 6 \\
\hline Non-sporulating fungi & 24 & 15 & 20 & 13 \\
\hline
\end{tabular}

* Isolates obtained on BYA medium inoculated with the initial suspension $(0.1 \mathrm{ml})$ diluted 100 -fold at heading and flowering and 1000-fold at the other stages

In 2009 the first sampling of ears (at heading) was conducted seven days following the fungicide Prosaro application (June 1) and the total numbers of fungi on winter wheat ears at this stage were lower in CFS than in EFS, 
but the differences were statistically significant only in the case of cv. Bogatka (Table 3). In this year, in contrast to the previous one, the highest populations of yeasts and mycelial fungi were detected on ears sampled at the flowering stage of their development (GS 65-69). At flowering ears of cv. Bogatka grown in CFS contained lower numbers of total fungi than ears grown in EFS, but in the case of cv. Legenda the opposite was true. At the milk kernels and hard kernels stages ears of both winter wheat cultivars grown in EFS were colonized by higher populations of filamentous fungi and yeasts than ears grown in CFS, however at the last stage the differences were generally insignificant (Table 3 ).

Table 3

Total numbers of fungi (cfu x $10^{4}$ ) including yeasts (in brackets) on winter wheat ears

(1 g d.m.) as influenced by their developmental stages and cultivation system (2009)

\begin{tabular}{ccccc}
\hline \multirow{2}{*}{$\begin{array}{c}\text { Cultivation sys- } \\
\text { tem }\end{array}$} & Heading & Flowering & Milk kernels & Hard kernels \\
\cline { 2 - 5 } & \multicolumn{5}{c}{ Cultivar Bogatka } \\
\hline Conventional & $0.64(0.44)$ & $121.4(115.7)$ & $23.20(21.70)$ & $34.80(11.50)$ \\
Ecological & $3.58(3.36)$ & $564.6(547.6)$ & $126.3(93.40)$ & $41.80(13.60)$ \\
\hline \multicolumn{5}{c}{ Cultivar Legenda } \\
\hline Conventional & $0.27(0.07)$ & $124.6(118.8)$ & $18.90(12.60)$ & $32.80(16.50)$ \\
Ecological & $0.35(0.12)$ & $76.73(71.34)$ & $112.1(99.20)$ & $51.60(30.90)$ \\
\hline \multirow{2}{*}{ LSD ${ }_{(0.05)}$ for: } & 0.45 & 59.4 & 29.3 & n.s. \\
cultiv. system & $(0.44)$ & $(68.2)$ & $(15.0)$ & $(7.0)$ \\
LSD $_{(0.05)}$ for: & 0.45 & 59.4 & n.s. & n.s. \\
cultivar & $(0.44)$ & $(68.2)$ & $($ n.s. $)$ & $(7.1)$ \\
LSD $_{(0.05)}$ cultiv. & 0.64 & 84.0 & n.s. & n.s. \\
syst. $\times$ cultivar & $(0.64)$ & $(96.4)$ & $($ n.s. $)$ & (n.s. $)$ \\
\hline
\end{tabular}

The results of quantitative analysis, shown in Table 4, indicate that in 2009 the species composition of filamentous fungi isolated from the examined ears was richer than that in the previous year, particularly with respect to the genus Fusarium. At flowering 4 isolates of $F$. poae were obtained from ears of cv. Bogatka grown in CFS and a single isolates of $F$. avenaceum and $F$. sporotrichioides from ears of cv. Legenda. On ears at the milk kernel stage two Fusarium species were identified, of which $F$. sporotrichioides predominated (18 isolates) on the ears of cv. Legenda in CFS and $F$. poae (9 isolates) on the ears of cv. Bogatka in EFS. On the ripening ears the occurrence of six Fusarium species was detected, of which the predominating species were: $F$. poae (39 isolates), F. crookwellense (18 isolates) and $F$. tricinctum 17 isolates). At this stage more Fusarium isolates were obtained form winter wheat ears grown under EFS than under CFS (Table 4). 
Number of filamentous fungi isolates* obtained from winter wheat ears as influenced by their developmental stages and cultivation system $(E=$ ecological, $C=$ conventional, 2009)

* Isolates obtained on BYA medium inoculated with the initial suspension $(0.1 \mathrm{ml})$ diluted 100 -fold at heading and flowering and 1000-fold at the other stages

\begin{tabular}{|c|c|c|c|c|}
\hline Fungi & Legenda E & Legenda C & Bogatka E & Bogatka C \\
\hline \multicolumn{5}{|c|}{ Heading } \\
\hline Alternaria alternata & 1 & - & - & - \\
\hline Alternaria tenuissima & 1 & - & - & - \\
\hline Cladosporium herbarum & 11 & 7 & 4 & 10 \\
\hline Penicillum sp. & 1 & - & 1 & - \\
\hline Non-sporulating fungi & 16 & 10 & 7 & 9 \\
\hline \multicolumn{5}{|c|}{ Flowering } \\
\hline Botrytis cinerea & - & 1 & - & - \\
\hline Cladosporium herbarum & 15 & 16 & 45 & 21 \\
\hline Fusarium poae & - & - & - & 4 \\
\hline Fusarium avenaceum. & 1 & - & - & - \\
\hline Fusarium sporotich. & - & 1 & 1 & - \\
\hline Penicillum sp. & - & - & 8 & - \\
\hline Non-sporulating fungi & 4 & 4 & 4 & 6 \\
\hline \multicolumn{5}{|c|}{ Milk kernels } \\
\hline Alternaria alternata & 1 & - & 5 & 5 \\
\hline Botrytis cinerea & - & 1 & - & - \\
\hline Cladosporium herbarum & 62 & 23 & 56 & 46 \\
\hline Fusarium poae & 2 & 4 & 9 & - \\
\hline Fusarium sporotrich. & - & 18 & - & 1 \\
\hline Mucor hiemalis & - & - & - & 1 \\
\hline Penicillum $\mathrm{sp}$ & - & - & - & 1 \\
\hline Rhizopus sp. & - & - & 1 & - \\
\hline Non-sporulating fungi & 14 & 1 & 30 & 15 \\
\hline \multicolumn{5}{|c|}{ Hard kernels } \\
\hline Alternaria alternata & 7 & 3 & 9 & 18 \\
\hline Botrytis cinerea & 1 & - & - & - \\
\hline Cladosporium herbarum & 16 & 9 & 29 & 24 \\
\hline Fusarium avenaceum & 2 & - & - & - \\
\hline Fusarium crookwellense & 1 & - & 17 & - \\
\hline Fusarium poae & 1 & 3 & 13 & 22 \\
\hline Fusarium sporotich. & - & 1 & - & 1 \\
\hline Fusarium tricinctum & 15 & 1 & 1 & - \\
\hline Fusarium sp & - & 7 & - & 2 \\
\hline .Non-sporulating fungi & 10 & 15 & 20 & 15 \\
\hline
\end{tabular}




\section{DISCUSSION}

In 2008 the first spraying of winter wheat plants with fungicides (mixture of Tilt Plus and Unix 75WG) in CFS was done on May 7 and the second one with Prosaro 250EC on May 30, and three days later (June 2) the first sampling of ears was performed. At this sampling significantly more fungi, both filamentous fungi and yeasts, were found on winter wheat ears grown in the conventional farming system (CFS) than in the ecological system (EFS) (Table 1). In CFS heading of winter wheat plants started about 2-3 days earlier than in EFS, thus in CFS ears were exposed to air contamination for several days longer than in EFS. This difference in connection with relatively short time ( 3 days) between the fungicide Prosaro application and ears sampling could be an explanation for the lack of an inhibitory effect of the fungicide on fungal communities colonizing ears in CFS as compared to EFS. This explanation could be supported by the results obtained in 2009 . In this year the first sampling of ears was done seven days after spraying of winter wheat plants with the fungicide Prosaro. This longer exposure of fungal populations occurring on ears to the fungicide resulted in a substantial reduction of their numbers on ears at the heading stage in CFS as compared to EFS (Table 3). In general, at the flowering and milk kernels stages of ears development markedly lower numbers of fungi, including yeasts, were detected on winter wheat ears grown in CFS than in EFS in both growing seasons and this reduction could be attributed mainly to the fungicides applied in CFS. It is also important to point out that at these two stages of ears development yeasts predominated within fungal communities colonizing ears of both winter wheat cultivars and their shares in the total fungal propagules occurring on ears ranged from about $70 \%$ to $97 \%$. Our results are in accord with those reported by Magan and Lacey (1986) who showed that fungicides generally reduced populations of saprophytic filamentous fungi (e.g. Cladosporium spp.) and yeasts on leaves and ears of field grown spring and winter wheat. In these and other studies (Buch and Burpee, 2002; De Azeredo et al., 1998; Dik et al., 1992) yeasts and yeastlike fungi also predominated within fungal communities colonizing the above-ground parts of plants.

In 2008 the highest numbers of fungi, with yeasts as predominating group (82\%-90\%), were found on fully ripened ears sampled on July 21, but in 2009 the most numerous fungal populations (with 93\%-97\% of yeasts) occurred on ears sampled at flowering (June 20) and at ripening (the last sampling on July 22) numbers of fungi on ears markedly dropped, mainly due to a substantial decrease of the share of yeasts (33\%-59\%) in the total numbers of fungi (Tables 1 and 3). These differences could be related to weather conditions which in 2008 were characterized by dry and hot June and similar weather in the first decade of July, but in 2009 June 
was wet (20 days with rainfalls) followed by dry and hot weather, particularly in the second decade of July ( http://www.iung.pulawy.pl/images/pdf/ Dobor_odmian_ekologia.).

The studied factors (farming systems) and weather conditions influenced also the qualitative composition of filamentous fungi colonizing winter wheat ears during their development. We were particularly interested in the fungi belonging to the genus Fusarium. It is well known that many species of this genus under favorable conditions are able to infect heads of cereal (FHB - Fusarium head blight) and, under favorable weather conditions, to produce various toxins contaminating the infected grain (Kiecana et al., 2005; Kwaśna et al. 1991; Łukanowski and Sadowski 2005; Magan and Lacey 1986, Perkowski et al., 1996; Wakuliński and Chełkowski, 1993). Generally, in 2009 more isolates of various filamentous fungi, including Fusarium species, were obtained from the studied winter wheat ears than in the previous year, probably mainly due to the above mentioned differences in weather conditions, particularly in June. In 2008 at the flowering stage, the most important developmental stage in cereals for ears infections by Fusarium spp. (Kiecana et al., 2005; Mesterhazy A., 1978; Perkowski et al., 1996; Wakuliński and Chełkowski, 1993), no Fusarium species were isolated, but in 2009 with wet weather at this stage three Fusarium species ( $F$. avenaceum, $F$. poae, $F$. sporotichioides) were found to occur on ears of both winter wheat cultivars (Table 4). The most pronounced effect of the compared farming systems on the occurrence and species composition of Fusarium fungi colonizing ears of winter wheat grown under these systems was found at the ripening stage. In 2008 more Fusarium isolates were obtained from ears of both winter wheat cultivars grown under CFS than under EFS (Table 2). Earlier we reported similar results for two other winter wheat cultivars (Roma and Zyta) grown under the same farming systems in 2007 (Martyniuk et al., 2009). Weather conditions in 2007, particularly scanty rainfalls in June and July, were very similar to those in 2008, but in 2009 markedly more rainfalls occurred during flowering and ripening, and in this year the highest numbers of Fusarium, both in terms of species and isolates, were present on the studied ears (Table 4). In 2009, contrary to the previous years, slightly more isolates of Fusarium species were obtained from winter wheat ears grown in EFS than in CFS. It seems that these differences might be explained, at least partially, by the differences in the winter wheat stands "architecture". The stands of winter wheat cultivars grown in CFS are usually denser and shorter than those in EFS (Kuś et al., 2007). In the years with dry weather conditions during June (at flowering and milk kernels), like those occurring in 2007 and 2008, ears in denser and shorter winter wheat stands in CFS might preserve moisture (e.g. dew droplets) for a longer period of time during the day than ears in sparser stands in EFS, making more favorable conditions for ears colonization by Fusarium fungi 
in CFS, as compared to EFS. In the years with frequent rainfalls, like those in 2009, stands "architecture" seems to play less important role in the colonization of winter wheat ears by fungi, including Fusarium species.

\section{CONCLUSIONS}

1. Ears of winter what grown under the conventional farming system (CFS) are usually colonized by less numerous communities of fungi, than ears under the ecological farming system (EFS).

2. Yeasts are predominating group of fungi occurring on winter wheat ears, particularly on ears being at the flowering and milk kernel stages of their development.

3. In the years with dry weather conditions during June (at flowering and milk kernels), ears in denser and shorter winter wheat stands in CFS might preserve moisture (e.g. dew droplets) for a longer period of time during the day than ears in sparser stands in EFS, making more favorable conditions for ears colonization by Fusarium fungi in CFS, as compared to EFS. In the years with frequent rainfalls stands "architecture" seems to play less important role in the colonization of winter wheat ears by fungi, including Fusarium species.

\section{REFERENCES}

Buck J.W., Burpee L.L., 2002. The effects of fungicides on phylloplane yeast populations of creeping bentgrass. Can. J. Microbiol., 48(6): 522-529.

De Azeredo L.A.I., Gomes E.A.T., Mendonca-Hagler L.C., Hagler A.N., 1998. Yeast communities associated with sugarcane in Campos, Rio de Janeiro, Brazil. Internatl Microbiol., 1: 205-208.

Dik A.J., Fokkema N.J., Van Pelt J.A., 1991: Consumption of aphid honeydew, a wheat yield reducing factor, by phyllosphere yeasts under field conditions. Neth. J. Pl. Pathol. 97: 209-232.

Dik A.J, Fokkema N.J., Van Pelt J.A., 1992: Influence of climatic and nutritional factors on yeast population dynamics in phyllospere of wheat. Microb. Ecol. 23: 41-52.

Domsch K.H., Gams W., Anderson T-H., 1980: Compendium of soil fungi. Acad. Press. London, New York, Toronto, Sydney.

Fokkema N.J., Riphagen I., Poot R., De Jong C., 1983: Aphid honeydew, a potential stimulant of Cochliobolus sativus and Septoria nodorum and the competitive role of saprophytic mycoflora. Trans. Br. Bycol. Soc. 81: 355-363.

Fokkema N.J., Dik A.J., Daamen R.A., 1987: Use of cerbendazim and carbendazim-resistant yeasts to create different yeast densities on wheat leaves for studies on biological control. Neth. J. Pl. Pathol. 93: 273283.

Kiecana I., Mielniczuk E., Perkowski J., Goliński P., 2005: Porażenie wiech przez Fusarium poae (Peck) Wollenw. oraz zawartość mikotoksyn w ziarnie owsa. Acta Agrobot., 59(2): 91-102.

Kuś J., Jończyk K., Kawalec A., 2007: Factors limiting the yields of winter wheat in different crop production systems. Acta Agrophys., 10(2): 407-417.

Kwaśna H., Chełkowski J., Zajkowski P., 1991: Fungi, t.XXII (in Polish), PAN, Instytut Botaniki, pp. 152.

Leslie J.F., Summerell B.A., 2006: The Fusarium Laboratory Manual. Blachwell Publishing, Ames, USA, pp. 388.

Lindow S.L., Brandl M.T., 2003: Microbiology of phyllosphere, Appl. Environm. Microbiol. 69: 1875-1883. 
Łukanowski A., Sadowski Cz., 2005: The use of PCR assay for quality testing of grain of winter wheat cultivated in organic, integrated, conventional system and monoculture in phytopathological aspect (in Polish). Acta Agrobot. 59 (2): 55-69.

Magan N., Lacey J., 1986: The phylloplane microflora of ripening wheat and effect of late fungicide applications. Ann. Appl. Biol. 109, 1: 117-128.

Martyniuk S., Gajda A., Kuś J., 2001: Microbiological and biochemical properties of soils under cereals grown in the ecological, conventional and integrated systems. Acta Agroph. 52: 185-192.

Martyniuk S., Oroń J., Mączka M., 2009: Charakterystyka mikroorganizmów występujących na kłosach pszenicy ozimej uprawianej w systemie konwencjonalnym i ekologicznym. Post. Ochr. Rośl./Prog. Plant Prot. 49(3): 1309-1316.

Mesterhazy A., 1978: Comparative analysis of artificial inoculation methods with Fusarium spp. on winter wheat varieties. Phytopathol. 93(1): 12-25.

Perkowski J., Kiecana I., Schumacher U., Muhler H.M., Chełkowski J., Goliński P., 1996: Head blight and biosynthesis of Fusarium toxins in barley kernels field inoculated with Fusarium culmorum. Eur. J. Pathol. 102: 491-496.

Wakuliński W., Chełkowski J., 1993: Fusarium species transmitted with seed of wheat, rye, barley, oats and triticale. Hod. Rośl. Aklim. i Nasien. 37: 131:136.

http://www.iung.pulawy.pl/images/pdf/Dobor_odmian_ekologia.pdf 